\title{
Desenvolvimento de Escala para Avaliação do Suporte Social em HIV/aids
}

\author{
Eliane Maria Fleury Seidl ${ }^{1}$ \\ Bartholomeu T. Tróccoli \\ Universidade de Brasília
}

\begin{abstract}
RESUMO - O estudo investigou a estrutura fatorial e as propriedades psicométricas da Escala de Suporte Social para Pessoas Vivendo com HIV/aids, elaborada com base em itens de uma escala canadense para avaliação do suporte social em pessoas soropositivas, em iniciativas de pesquisadores brasileiros e na revisão da literatura sobre o construto suporte social. A amostra de validação foi composta de 241 pessoas soropositivas (66,8\% homens), com idades entre 20 a 64 anos $(M=37,4)$. A análise fatorial exploratória, pelo método dos fatores principais e rotação oblíqua, indicou a existência de dois fatores de primeira ordem: suporte social emocional (12 itens, $\alpha=0,92)$ e suporte social instrumental $(12$ itens, $\alpha=0,84)$. Um fator de segunda ordem composto dos 24 itens originais foi identificado, com bons indicadores psicométricos $(\alpha=0,87)$. A estrutura fatorial encontrada correspondeu à estrutura esperada de um instrumento para avaliar as principais dimensões do suporte social em pessoas HIV+.
\end{abstract}

Palavras-chave: suporte social; análise fatorial; HIV/aids.

\section{Development of a Scale for the Social Support Evaluation in HIV/Aids}

\begin{abstract}
This study investigated the factorial structure and the psychometric properties of The Social Support Scale for People with HIV/Aids based on items from a canadian scale for evaluation of the social support for people living with HIV/aids, on initiatives of brazilian researchers and on the revision of the literature about the social support construct. The validation sample was composed of $241 \mathrm{HIV}$ positive individuals (66.8\% males), with ages between 20 and 64 years old ( $M=37.4$ years). The exploratory factorial analysis using the principal axis extraction method and oblique rotation revealed two first order factors: emotional social support (12 items, $\alpha=0.92)$ and instrumental social support $(12$ items, $\alpha=0.84)$. A second order factor was also identified with all 24 original items, with good psychometric indicators $(\alpha=0.87)$. The factorial structure found corresponded to what is expected from an instrument aimed at measuring the major social support dimensions of people who are HIV positive.
\end{abstract}

Key words: social support; factorial analysis; HIV/Aids.

O construto suporte social surgiu de modo proeminente na literatura em psicologia e em áreas correlatas a partir de meados dos anos 1970. Os trabalhos pioneiros de Cassel (1976) e Cobb (1976) tiveram grande relevância ao apontar a influência das interações sociais sobre o bem-estar e a saúde das pessoas. Esses estudos buscavam compreender como a inexistência ou a precariedade do suporte social poderia aumentar a vulnerabilidade a doenças, e como o suporte social protegeria os indivíduos de danos à saúde física e mental decorrentes de situações de estresse.

Em seu trabalho de revisão da literatura, Cobb (1976) selecionou estudos que mostravam os efeitos protetores do suporte social em situações de estresse ao longo da vida. Concluiu que a adequação do suporte poderia ter efeitos protetores em momentos de crise, como luto, aposentadoria, desemprego, recuperação de doenças e hospitalização. Nas pesquisas, realizadas nas décadas de 1960 e 1970, foi possível identificar, contudo, dificuldades para definir e, conseqüentemente, avaliar o suporte social. As principais

1 Endereço: Instituto de Psicologia, Campus Darcy Ribeiro, Brasília, DF, Brasil, 70910-900.E-mail: seidl@unb.b1 falhas metodológicas consistiam na precária consistência interna dos instrumentos utilizados, escalas sem análise da estrutura fatorial, bem como escalas criadas post hoc de um conjunto de dados (Cohen \& Wills, 1985; Thoits, 1982).

Um das primeiras conceituações de suporte social referia-se à "informação que leva o indivíduo a acreditar que ele é cuidado, amado, estimado e que pertence a uma rede social com obrigações mútuas" (Cobb, 1976, p. 300). Nesse sentido, os efeitos do suporte social levariam ao sentimento e à percepção de estima e pertencimento a uma rede social com direitos e deveres comuns.

Os estudos sobre suporte social podem ser divididos em duas categorias, de acordo com a conceituação e o tipo de medida focalizada: aspectos estruturais e funcionais do suporte. Os estudos que investigam os aspectos estruturais detêm-se na frequiência ou quantidade de relações sociais, interessados, portanto, na integração da pessoa em uma rede social (social network). De modo geral, trabalham com indicadores como tamanho da rede (número de pessoas envolvidas), homogeneidade, reciprocidade, acessibilidade e frequiência do contato, além dos tipos de papéis sociais que as pessoas desenvolvem na rede, incluindo a participação 
em instituições como família, grupos religiosos, comunitários, entre outros. As medidas dessa modalidade de suporte analisam, em suma, o nível de integração versus o de isolamento da pessoa em uma rede social (Thoits, 1995).

O componente funcional, por sua vez, refere-se à extensão em que as relações sociais podem cumprir determinadas funções. Assim, a análise dos aspectos funcionais do suporte social volta-se para a percepção quanto à disponibilidade e ao tipo de apoio recebido, abarcando ainda a satisfação com o mesmo. Dessa forma, a percepção das interações sociais como suportivas baseia-se na avaliação subjetiva quanto às necessidades e às expectativas de apoio social da pessoa (McNally \& Newman, 1999). Duas categorias de suporte funcional têm prevalecido na literatura: instrumental ou operacional e emocional ou de estima. A primeira categoria refere-se à disponibilização de ajuda que auxilie a pessoa no manejo ou resolução de situações práticas ou operacionais do cotidiano, como apoio material, financeiro ou das atividades diversas do dia-a-dia. O suporte emocional ou de estima consiste em comportamentos como escutar, prover atenção ou fazer companhia que contribuem para que a pessoa se sinta cuidada e/ou estimada. Alguns estudos incluem ainda a categoria suporte de informação, que corresponde aos conselhos e informações recebidos que auxiliem o indivíduo a avaliar e a lidar com situações difíceis e estressantes (Cohen \& Wills, 1985; Winemiller, Mitchell, Sutliff \& Cline, 1993). Apesar de se mostrarem como fatores independentes, os estudos empíricos têm identificado alguma intercorrelação entre essas duas medidas dos suportes funcionais, chegando a constituir, em alguns casos, um único fator (Thoits, 1995).

\section{Modelos Teóricos Sobre Suporte Social: Buffer e Efeito Principal}

Dois modelos teóricos têm norteado os estudos sobre suporte social: o de buffer e o do efeito direto ou principal (Cohen \& Wills, 1985; Thoits, 1995). Para o primeiro modelo, o suporte social é protetor ao amenizar as conseqüências negativas de eventos estressantes sobre o bem-estar físico e psicológico. Assim, a hipótese de buffer aponta que "indivíduos com um forte sistema de suporte social devem lidar melhor com as principais mudanças na vida; aqueles com pouco ou nenhum suporte estariam mais vulneráveis às mudanças, em especial aquelas indesejáveis" (Thoits, 1982, p. 145). Nessa perspectiva, as características funcionais do suporte têm sido mais adequadas para avaliar a hipótese de buffer, já que o requerimento metodológico para testar esse modelo prevê a existência de situações ou de eventos estressantes; assim, o apoio social poderia diminuir a percepção de ameaça ou perda, funcionando como um recurso ambiental importante no processo de enfrentamento.

A busca de suporte social pode constituir, inclusive, uma estratégia de coping, voltada para o manejo da situação ou do estressor (Seidl, Tróccoli \& Zannon, 2001). A associação entre suporte social e enfrentamento parece estar relacionada aos seguintes aspectos (Thoits, 1995): a) os apoiadores podem auxiliar na reavaliação (reappraisal) da situação estressante ou facilitar a utilização de determinadas estratégias de enfrentamento, como as orientadas para o problema; b) os apoiadores ajudam a manter a auto-estima da pessoa em situação de estresse; c) eles propiciam feedba$c k$ e encorajamento, mantendo um sentido de competência e domínio da situação.

No segundo modelo - efeito direto ou principal - os recursos sociais são considerados benéficos independentemente do indivíduo estar ou não em situação de estresse (Cohen \& Wills, 1985). Assim, medidas sobre a integração em redes sociais são mais utilizadas quando esse é o modelo estudado. Busca-se comumente a associação entre suporte social e bem-estar, atribuída a um efeito benéfico geral do apoio social, a partir da avaliação do grau de isolamento versus a integração da pessoa em uma rede social. Comparando os dois modelos, estudiosos concluem que tanto o do efeito principal quanto o funcional parecem ter impacto benéfico sobre o bem-estar (Ferrero, Barreto \& Toledo, 1998). Nesse sentido, Cohen e Wills (1985) afirmaram que:

as funções específicas do suporte são responsivas a eventos estressantes, enquanto a integração em rede social opera para manter sentimentos de estabilidade e auto-estima, independente do nível de estresse; assim, a integração em rede social e o suporte funcional parecem representar diferentes processos nos quais os recursos sociais influenciam o bem-estar (p. 349).

Alguns pesquisadores, no entanto, argumentam que os estudos sobre a estrutura da rede e o nível de integração social não valorizam o significado das relações sociais para o indivíduo, pois contar o número de relacionamentos ou a atividade social da pessoa não abarca os aspectos subjetivos implicados no conceito (McNally \& Newmam, 1999). Reforçam, assim, o conceito de suporte social na concepção funcional, valorizando a avaliação da pessoa e a satisfação com o suporte. Essa verificação também se evidencia no trabalho de Winemiller e cols. (1993) que, ao proceder a uma revisão de literatura sobre instrumentos de mensuração do suporte social, observaram que a maioria $(69,1 \%)$ investigava o suporte na perspectiva funcional nas modalidades emocional e instrumental.

Nos anos 1990, os estudos sobre suporte social deram continuidade à investigação acerca do seu impacto na saúde física e mental. Assim, observou-se um interesse crescente pelas relações do suporte social com estresse, enfrentamento, bem-estar psicológico e percepção da qualidade de vida (Holahan, Holahan, Moos \& Brennan, 1995; Penninx \& cols., 1998).

Após cerca de 30 anos de pesquisas, Thoits (1995) sintetiza algumas conclusões em relação ao construto suporte social: a) as medidas estruturais de integração social parecem relacionadas à saúde física e mental, no entanto, há indícios de que a integração social não protege do impacto emocional decorrente de estressores específicos; b) o suporte funcional emocional parece ter melhores resultados como protetor da saúde física e mental diante de estresso- 
res do curso de vida, conclusão baseada nos achados sobre os benefícios decorrentes da existência de pelo menos uma pessoa íntima e confidente, independente do tipo de vínculo (cônjuge, parente ou amigo); c) estudos sobre suporte social e gênero mostram que os homens tendem a ter redes mais amplas e diversificadas (relacionamentos extensivos), enquanto as mulheres tendem a investir mais em relacionamentos com intimidade; d) há alguma consistência no achado de que pessoas casadas ou vivendo com companheiro/a referem mais suporte percebido.

\section{Suporte Social e Pessoas Vivendo com HIV/aids}

No campo da psicologia da saúde, suporte social é um construto que tem despertado grande interesse na medida em que a disponibilidade e a satisfação com o apoio social parecem afetar o ajustamento de pessoas portadoras de enfermidades crônicas. À guisa de exemplo, pesquisas sobre suporte social e adesão ao tratamento em condições de cronicidade (DiMatteo, 2004) e sobre a relação entre suporte social e a ocorrência de depressão em pessoas com doenças crônicas (Symister \& Friend, 2003) têm sido desenvolvidas, apontando a atualidade de estudos sobre esse construto associado a temas importantes do âmbito da psicologia aplicada à saúde.

$\mathrm{Na}$ área do HIV/aids, o suporte social também tem sido objeto de interesse, principalmente devido às situações de preconceito que ainda caracterizam as reações sociais à soropositividade. Em conseqüência, o estigma e a discriminação podem levar ao isolamento social, à restrição dos relacionamentos sociais e às dificuldades no campo afetivosexual, com impacto negativo na manutenção e estruturação da rede social de apoio de pessoas soropositivas (Green, 1993).

Nessa perspectiva, estudos têm investigado o impacto do suporte social percebido e das estratégias de enfrentamento sobre o bem-estar psicológico de pessoas portadoras do HIV/aids. Assim, Fukunishi e cols. (1997) verificaram que suporte social limitado e enfrentamento de esquiva estiveram associados a sintomas depressivos em pacientes japoneses soropositivos assintomáticos. Em outro estudo, examinou-se a relação entre estresse, sintomas depressivos e suporte social na progressão da infecção para o HIV, em homens soropositivos assintomáticos. O estudo longitudinal mostrou que, após cinco anos, a probabilidade de desenvolver aids era duas a três maiores em pessoas que estavam acima da mediana em estresse e abaixo da mediana em suporte social. Os autores concluíram que maior vivência de estresse e menos suporte social podem acelerar o curso da infecção pelo HIV (Leserman \& cols., 1999).

Em outra pesquisa com delineamento prospectivo e acompanhamento de sete anos, Leserman e cols. (2000) investigaram o impacto de eventos estressantes, do suporte social, do enfrentamento e dos níveis de cortisol em relação à progressão para aids. Uma progressão mais rápida para a enfermidade aids esteve associada à média acumulada mais elevada de estressores, enfrentamento de esquiva, ta- xas mais elevadas de cortisol e indicadores acumulativos de baixa satisfação com o suporte social. A conclusão apontou para a necessidade de novos estudos que identificassem as intervenções psicossociais que poderiam influenciar a progressão para aids, pautando-se nesses achados.

Pesquisas têm mostrado ainda o impacto da condição de soropositividade sobre os cuidadores - familiares ou pessoas da rede social informal, como amigos e voluntários - que participam dos cuidados à saúde de crianças e adultos soropositivos. São pessoas que integram a rede social de apoio, convivendo cotidianamente com questões relacionadas ao HIV/aids (Klunklin \& Harrigan, 2002; Turner, Pearlin \& Mullan, 1998).

O suporte social tem sido investigado também em estudos sobre adesão ao tratamento anti-retroviral. Sing e colaboradores (1999) observaram que a satisfação com o suporte social, e a utilização de enfrentamento comportamental ativo, estiveram associadas à adesão ao tratamento. Nesse estudo, a importância do suporte social foi apontada por sua influência direta - disponibilização de encorajamento, reforço positivo e motivação para o auto-cuidado -, e indireta, ao atenuar estímulos que interferiam negativamente sobre a adesão. Em estudo mais recente, Gonzalez e cols. (2004) constataram que apoio social e o bem-estar psicológico estiveram relacionados à conduta de adesão à terapia anti-retroviral.

$\mathrm{Na}$ prática clínica em saúde com pacientes soropositivos, entrevistas estruturadas e semi-estruturadas têm sido utilizadas como métodos preferenciais para avaliar a percepção e a satisfação com o suporte social (Seidl, 2001). No entanto, considerando a relevância da análise do suporte social nas práticas profissionais em HIV/aids, bem como dos estudos sobre o ajustamento à condição de soropositividade e à adesão à terapia anti-retroviral, é urgente o desenvolvimento de instrumentos com estrutura fatorial conhecida e fundamentada na literatura científica.

Um instrumento para mensuração do suporte social percebido e da satisfação foi construído e validado no Canadá, denominado Social Support Inventory for People who are Positive or Have Aids (Renwick, Halpen, Rudman \& Friedland, 1999), específico para pessoas soropositivas. Este instrumento foi desenvolvido com base em estudos sobre o suporte social para a população em geral e para pessoas acometidas por condições médicas específicas, como HIV/ aids. A importância do desenvolvimento de instrumento com estrutura fatorial estabelecida, que inclua itens relativos à satisfação com o suporte social, se deve também à constatação de que pesquisas realizadas no país - voltadas especificamente para a avaliação do suporte social em HIV/ aids -, usaram instrumentos sem menção à análise da estrutura fatorial (cf., Lovisi \& Morgado, 1996).

O objetivo do presente estudo, portanto, foi investigar a estrutura fatorial e as propriedades psicométricas de uma escala especialmente desenvolvida para o estudo do suporte social em pessoas soropositivas para o HIV. Nessa perspectiva, a Escala de Suporte Social para Pessoas Vivendo com HIV/aids foi submetida à análise fatorial exploratória e a 
testes de confiabilidade (alpha de Cronbach). Esta escala foi derivada de instrumento canadense para mensurar o suporte social em pessoas vivendo com HIV/aids (Renwick \& cols., 1999), bem como em iniciativas de pesquisadores brasileiros que trabalharam com o conceito (Freitas, 1997) e na revisão de literatura sobre o tema (Friedland, Renwick \& McColl, 1996; Winemiller \& cols., 1993).

\section{Método}

\section{Participantes}

A amostra foi composta de 241 pacientes com sorologia positiva para o HIV, que aceitaram participar de um estudo sobre qualidade de vida, enfrentamento e suporte social em pessoas vivendo com HIV/aids, sendo 161 (66,8\%) do sexo masculino e $80(33,2 \%)$ do sexo feminino. A idade variou de 20 a 64 anos $(M=37,4 ; D P=7,8)$.

No que se refere à escolaridade, $33,2 \%$ tinham o ensino fundamental incompleto e completo, $35,7 \%$ estudaram até o ensino médio completo, $12,9 \%$ tinham curso superior incompleto e 17,8\% o superior completo. Quanto à situação conjugal, $41,9 \%$ estavam casados ou viviam em união consensual e a maioria $(58,1 \%)$ estava vivendo sem parceiro(a), estando solteira, separada, divorciada ou viúva. Pouco mais da metade da amostra tinha filhos $(51,1 \%)$.

No que concerne à situação empregatícia, o maior percentual foi de pessoas que estavam empregadas com direitos trabalhistas $(31,5 \%)$, seguidas daquelas que possuíam atividade autônoma regular $(13,7 \%)$. O percentual de desempregados foi de $12,9 \%$ e o de aposentados alcançou $29,5 \%$.

Os participantes faziam tratamento em dois serviços da rede pública de saúde do Distrito Federal, e estavam em acompanhamento ambulatorial. O tempo do diagnóstico de soropositividade variou de menos de um ano a 14 anos $(M=4,3$ anos; $D P=3,3)$. Um terço dos participantes era assintomática e $70 \%$ eram sintomáticos na medida em que já tinham apresentado sinais e sintomas da aids. A grande maioria $(86 \%)$ estava em uso de medicamentos anti-retrovirais no momento da pesquisa.

Os valores da contagem dos linfócitos T CD4+ (número de células por milímetro cúbico de sangue), indicador importante da integridade do sistema imunológico, variaram de 2 a $1.728(M=409,3 ; D P=277)$, sinalizando a grande variabilidade desse indicador na amostra. A carga viral plasmática, medida pela quantidade de cópias virais por mililitro (ml) de sangue periférico, foi descrita em número absoluto de cópias virais. Variou de 80 cópias $/ \mathrm{ml}$ (denominada indetectável, menor carga viral cuja identificação é possível com base na tecnologia disponível) até 2.350 .000 cópias $(M=51.694$; $D P=188.069,7)$. Quase um terço $(28,2 \%)$ dos participantes estava com carga viral indetectável, fato que expressa a eficácia do tratamento anti-retroviral em boa parte da amostra.

\section{Instrumentos}

Escala de Suporte Social para Pessoas Vivendo com HIV/ aids. Inicialmente foi feita a tradução reversa do instrumen- to Social Support Inventory for People who are Positive or Have AIDS (Renwick \& cols., 1999), com dois tradutores bilíngües, seguida da adaptação semântica de alguns itens. O instrumento canadense é composto de 54 itens, com escala de resposta tipo Likert de cinco pontos, podendo ser autoaplicado ou administrado mediante entrevista. Abrange três dimensões do suporte social: instrumental, emocional e de informação. Para cada item são investigados a disponibilidade de suporte, o interesse em receber suporte e a satisfação com o suporte. A estrutura fatorial da escala canadense apresenta índices precários de consistência interna, pois os alphas de Cronbach variaram de 0,89 a 0,37.

Uma primeira versão do instrumento foi testada em estudo piloto com 10 pessoas soropositivas, que possuíam níveis diversificados de escolaridade. O estudo-piloto apontou a necessidade de supressão e reagrupamento de itens, objetivando maior praticidade e menor redundância quanto ao conteúdo de alguns itens. Optou-se, então, pela manutenção de dois fatores com base em achados da literatura que indicam a maior relevância dos suportes emocional e instrumental (Freitas, 1997; Friedland \& cols., 1996; Winemiller \& cols., 1993). No entanto, foi mantido um item referente ao suporte de informação, incluído na subescala suporte emocional.

Após essas mudanças, o instrumento brasileiro adquiriu, de fato, estrutura diferente do instrumento canadense. A versão final, anterior ao teste empírico, ficou com 26 itens: 10 itens referentes ao suporte instrumental (cinco sobre disponibilidade e cinco sobre satisfação) e 16 itens do suporte emocional (oito sobre disponibilidade e oito sobre satisfação). As respostas foram dadas em escalas Likert de cinco pontos: (1) nunca a (5) sempre, para a disponibilidade de suporte, e de (1) muito insatisfeito a (5) muito satisfeito para satisfação com o suporte. No banco de dados, cada participante teve 26 variáveis correspondentes aos 26 itens do instrumento. As fontes de suporte, nas duas categorias, também foram pesquisadas. No final do instrumento foi incluída uma questão aberta, cuja resposta era opcional, indagando "Você tem recebido algum outro tipo de apoio de pessoas?". O objetivo foi identificar outra(s) modalidade(s) de apoio social relevante(s) para o paciente.

Questionários sociodemográfico e médico-clínico. Elaborados para o estudo, contendo questões para a caracterização sociodemográfica e médico-clínica da amostra.

\section{Procedimento}

O convite foi feito quando os pacientes estavam em sala de espera aguardando consulta, realizando exames laboratoriais ou buscando medicamentos anti-retrovirais na farmácia das unidades de saúde. Os instrumentos foram administrados mediante aplicação assistida, sendo que o tempo de preenchimento foi de aproximadamente 20 minutos. Os procedimentos para a obtenção do consentimento informado livre e esclarecido, o caráter voluntário da participação e demais aspectos éticos foram assegurados, sendo que o índice de recusa foi baixo (menos de $5 \%$ do total de pessoas 
convidadas).

A aplicação do instrumento foi individual e teve lugar em ambulatório ou sala das unidades de saúde escolhidas. A aplicação se deu da seguinte forma: de posse de uma cópia do instrumento, o paciente acompanhou a leitura em voz alta efetuada pelo pesquisador, que tinha outra cópia do instrumento em mãos. A instrução dada foi a seguinte:

"Este questionário é sobre o apoio ou ajuda que você tem recebido de diferentes pessoas com quem você se relaciona. Por favor, informe a freqüência dos diferentes tipos de apoio que têm recebido em relação à soropositividade e a sua satisfação em relação a cada um deles. Pedimos que não deixe nenhuma questão em branco. Mais uma vez, obrigada pela sua colaboração!"

Os pacientes preencheram o instrumento diante do pesquisador. Eventuais dúvidas foram esclarecidas, visando o preenchimento completo do instrumento, evitando itens em branco. Os questionários sociodemográfico e médico-clínico foram respondidos mediante entrevista feita pelo pesquisador, antes da aplicação do instrumento sobre suporte social.

\section{Análise de dados}

O tratamento dos dados baseou-se nos procedimentos recomendados por Tabachnick e Fidell (1996) para realização de análise fatorial exploratória. Foi utilizado o software SPSS (Statistical Package for Social Sciences) versão Windows 10.0. Detalhes da análise de dados estão descritos na seção Resultados.

\section{Resultados}

Inicialmente procedeu-se à análise estatística para identificação de dados faltosos, verificando-se que estes foram nulos devido à estratégia de aplicação utilizada. A análise das freqüências e da distribuição dos 26 itens indicou índices satisfatórios quanto à dispersão e à curtose, bem como a não existência de casos discrepantes (outliers) univariados. A investigação dos casos discrepantes (outliers) multivariados foi feita mediante análise de regressão múltipla, seguindo os procedimentos propostos por Tabachnick e Fidell (1996). Com base no critério da distância Mahalanobis $(p<0,001)$, foram identificados 14 casos discrepantes que foram filtrados, ficando a amostra final com 227 participantes. Gráficos de dispersão entre pares de variáveis mostraram que não havia problemas de ausência de linearidade.

Primeiramente foi realizada a extração dos componentes principais, quando se verificou a adequação da matriz correlacional quanto aos pressupostos necessários à análise multivariada, sem a presença de singularidade e multicolinearidade. O gráfico scree plot, considerando os eigenvalues maiores que 2, apontou a existência de dois fatores. $\mathrm{O}$ indicador $\mathrm{KMO}(0,855)$ mostrou que a fatorabilidade foi considerada satisfatória. Pelo método de fatoração dos eixos principais (principal axis factoring), rotação oblíqua (oblimin), foram extraídos dois fatores. Apenas itens com cargas fatoriais superiores a 0,38 (positiva ou negativa) foram incluídos. A consistência interna dos fatores foi analisada pelo alpha de Cronbach.

A estrutura fatorial encontrada foi a seguinte: o Fator 1, denominado suporte social emocional ( $\alpha=0,92,12$ itens), manteve os itens da subescala original, menos dois itens que migraram para o segundo fator. O item 6 ("Você tem recebido apoio de alguém que lhe ajuda a enfrentar melhor o seu problema de saúde?"), bem como o item correspondente que mediu a satisfação em relação a este aspecto, apresentaram cargas fatoriais equivalentes nos dois fatores, indicando baixa especificidade, fato que motivou a exclusão de ambos. O Fator 1 alcançou 39,6\% de variância explicada. Todos os itens referentes à satisfação com a modalidade de suporte emocional fizeram parte desse fator, com cargas fatoriais satisfatórias (Tabela 1).

O segundo fator ( $\alpha=0,84 ; 12$ itens), denominado suporte social instrumental, agrupou os itens do fator original mais dois itens da subescala do suporte emocional, explicando $8,9 \%$ da variância. O item que passou a integrar esse fator foi o de número 9: "Você tem recebido apoio de alguém com quem você pode contar em caso de necessidade?", juntamente com o item correspondente sobre satisfação. A análise semântica desse item, em especial devido ao termo necessidade, mostrou coerência com a noção de suporte social instrumental.

No sentido de manter maior coerência com pressupostos teóricos do conceito apontados na literatura, além dos indicadores alphas de Cronbach terem sido satisfatórios, optou-se por adotar essa estrutura fatorial com duas dimensões: suporte emocional e suporte instrumental. Finalmente, a escala foi composta com dois fatores, 24 itens, com as seguintes definições:

1. suporte emocional (12 itens) - percepção e satisfação quanto à disponibilidade de escuta, atenção, informação, estima, companhia e apoio emocional em relação à soropositividade;

2. suporte instrumental (12 itens) - percepção e satisfação quanto à disponibilidade de apoio no manejo ou resolução de questões operacionais do tratamento ou do cuidado de saúde, de atividades práticas do cotidiano, de ajuda material e/ou financeira.

A Tabela 1 apresenta os dois fatores, com os itens respectivos, cargas fatoriais, comunalidades, alphas de Cronbach e percentual de variância explicada.

Para a composição dos escores, estes foram calculados pela média aritmética dos valores dos itens correspondentes a cada fator (disponibilidade e satisfação), de modo que estes variaram de 1 a 5 para o suporte emocional e para o suporte instrumental.

\section{Análises fatoriais subseqüientes}

Verificou-se a existência de correlação entre os dois fatores igual a $0,57(p \leq 0,001)$. A magnitude da correlação indicou a importância de nova análise fatorial, sem rotação, para identificação dos fatores de segunda ordem. Voltando- 
Tabela 1. Solução fatorial com as cargas fatoriais, comunalidades, percentual de variância e Alphas de Cronbach da Escala de Suporte Social para Pessoas Vivendo com HIV/aids $(N=227)$.

\begin{tabular}{|c|c|c|c|c|}
\hline $\mathbf{N}^{\mathrm{o}}$ item & Item & F1* & $\mathbf{F} 2 * *$ & $h^{2}$ \\
\hline 12 & Você tem recebido apoio de alguém que lhe ajuda a melhorar o seu humor, seu astral? & 0,82 & & 0,780 \\
\hline $12 \mathrm{a}$ & Quão satisfeito/a você está em relação ao apoio recebido que lhe ajuda a melhorar o seu astral? & 0,81 & & 0,803 \\
\hline $13 \mathrm{a}$ & $\begin{array}{l}\text { Quão satisfeito/a você está em relação ao apoio recebido quando precisa de companhia para se divertir ou } \\
\text { fazer atividades de lazer? }\end{array}$ & 0,80 & & 0,835 \\
\hline 13 & $\begin{array}{l}\text { Você tem recebido apoio de alguém quando precisa de companhia para se divertir ou fazer atividades de } \\
\text { lazer? }\end{array}$ & 0,76 & & 0,808 \\
\hline $11 \mathrm{a}$ & Quão satisfeito/a você está em relação ao apoio recebido que faz você se sentir integrado socialmente? & 0,75 & & 0,806 \\
\hline 11 & Você tem recebido apoio de alguém que faz você se sentir integrado socialmente? & 0,73 & & 0,783 \\
\hline $8 \mathrm{a}$ & $\begin{array}{l}\text { Quão satisfeito/a você está em relação ao apoio recebido para desabafar ou conversar sobre assuntos } \\
\text { relacionados à enfermidade? }\end{array}$ & 0,73 & & 0,742 \\
\hline 8 & $\begin{array}{l}\text { Você tem recebido apoio de alguém com quem possa desabafar ou conversar sobre assuntos relacionados } \\
\text { à sua enfermidade? }\end{array}$ & 0,71 & & 0,647 \\
\hline 7 & Você tem recebido apoio de alguém que faz você se sentir valorizado/a como pessoa? & 0,68 & & 0,766 \\
\hline $7 \mathrm{a}$ & Quão satisfeito/a você está em relação ao apoio que faz você se sentir valorizado/a como pessoa? & 0,67 & & 0,774 \\
\hline $10 \mathrm{a}$ & $\begin{array}{l}\text { Quão satisfeito/a você está em relação ao apoio que lhe fornece informações, melhorando o nível de } \\
\text { conhecimento sobre o seu problema de saúde? }\end{array}$ & 0,48 & & 0,711 \\
\hline 10 & $\begin{array}{l}\text { Você tem recebido apoio de alguém que lhe fornece informações, melhorando o seu nível de conhecimento } \\
\text { sobre o seu problema de saúde? }\end{array}$ & 0,40 & & 0,690 \\
\hline 2 & $\begin{array}{l}\text { Você tem recebido apoio de alguém em questões financeiras, como divisão das despesas da casa, dinheiro } \\
\text { dado ou emprestado? }\end{array}$ & & 0,58 & 0,490 \\
\hline 4 & Você tem recebido apoio de alguém em relação ao seu próprio cuidado de saúde? & & 0,56 & 0,611 \\
\hline $2 \mathrm{a}$ & $\begin{array}{l}\text { Quão satisfeito/a você está em relação ao apoio em questões financeiras, como divisão das despesas da } \\
\text { casa, dinheiro dado ou emprestado? }\end{array}$ & & 0,55 & 0,534 \\
\hline 1 & $\begin{array}{l}\text { Você tem recebido apoio de alguém em situações concretas, facilitando a realização do seu tratamento } \\
\text { de saúde? }\end{array}$ & & 0,54 & 0,529 \\
\hline $1 \mathrm{a}$ & $\begin{array}{l}\text { Quão satisfeito/a você está em relação ao apoio recebido em situações concretas que facilitam a realização } \\
\text { do seu tratamento de saúde? }\end{array}$ & & 0,54 & 0,526 \\
\hline $3 \mathrm{a}$ & Quão satisfeito/a você está com o apoio recebido em atividades práticas do seu dia-a-dia? & & 0,54 & 0,613 \\
\hline $5 \mathrm{a}$ & $\begin{array}{l}\text { Quão satisfeito/a você está em relação ao apoio de pessoas que lhe dão coisas que você precisa em seu } \\
\text { dia-a-dia? }\end{array}$ & & 0,53 & 0,506 \\
\hline $4 \mathrm{a}$ & Quão satisfeito/a você está em relação ao apoio recebido para o seu próprio cuidado de saúde? & & 0,51 & 0,715 \\
\hline $9 \mathrm{a}$ & $\begin{array}{l}\text { Quão satisfeito/a você está em relação ao apoio recebido de quem você pode contar em caso de } \\
\text { necessidade? }\end{array}$ & & 0,48 & 0,794 \\
\hline 3 & Você tem recebido apoio de alguém em atividades práticas do seu dia-a-dia? & & 0,48 & 0,512 \\
\hline 9 & Você tem recebido apoio de alguém com quem pode contar em caso de necessidade? & & 0,47 & 0,750 \\
\hline \multirow[t]{4}{*}{5} & Você tem recebido apoio de pessoas que lhe dão coisas que você precisa em seu dia-a-dia? & & 0,39 & 0,613 \\
\hline & Número de itens & 12 & 12 & \\
\hline & Alpha de Cronbach & 0,92 & 0,85 & \\
\hline & Variância explicada & 39,6 & 8,9 & \\
\hline
\end{tabular}

\footnotetext{
* Fator 1 - suporte social emocional; ** Fator 2 - suporte social instrumental
}

se ao banco de dados original, após os procedimentos de limpeza já relatados, e a exclusão do item 6 e de seu correspondente sobre satisfação, procedeu-se a uma outra análise fatorial exploratória. O propósito foi investigar o desempenho da escala considerando-se a existência de um fator único, uma vez que a presença de correlação entre os fatores (justificando a rotação oblíqua) implica necessariamente na existência de um fator de segunda ordem. De fato, os resul- tados obtidos com a extração de um único fator, pelo método dos eixos principais, revelou um KMO igual a $0,87 \mathrm{e}$ eigenvalue de 5,1, com variância explicada total de $37,8 \%$. As cargas fatoriais dos itens variaram de 0,75 a 0,48 e o alpha de Cronbach foi equivalente a 0,87 . Procedeu-se, então, a composição de um escore único do suporte social, a partir da média aritmética dos 24 itens, para cada sujeito. Análise estatística descritiva mostrou média de 3,77 $(D P=0,69$; 
$M d n=3,87$; amplitude de 1,75 a 5,0). Concluiu-se que as duas versões - bifatorial ou unifatorial - são semelhantes quanto à validade de construto, sendo que a escolha quanto a usar uma ou outra depende dos objetivos do pesquisador e da investigação proposta.

\section{Suporte social e características sociodemográficas dos participantes}

Investigou-se ainda a associação entre as medidas dos suportes emocional e instrumental e variáveis sociodemográficas. As medidas de tendência central, distribuição e dispersão do suporte social emocional e instrumental estão apresentadas na Tabela 2, com base nos resultados da análise fatorial que indicou a presença de dois fatores. A variabilidade dos escores mostrou a diversidade na amostra quanto às duas variáveis: os participantes se distribuíram desde aqueles que percebiam alta disponibilidade e estavam satisfeitos com as duas modalidades de suporte social, até os que indicaram suporte social percebido precário ou nulo, acompanhado de muita insatisfação. No entanto, os indicadores de média e mediana, além da distribuição de ambos os escores, com simetria levemente à direita, indicaram que a maior parte dos participantes percebia disponibilidade e estava satisfeita com o suporte social emocional e instrumental.

Não se observou correlação entre idade e suporte emocional $(r=0,09 ; p=0,16)$ e instrumental $(r=0,04 ; p=0,57)$. Testes $t$ de Student exploraram diferenças entre os escores médios nas duas modalidades de suporte quanto ao sexo, escolaridade, situação conjugal e condição clínica (sintomático ou assintomático). Em relação ao suporte emocional, foram observadas diferenças estatísticas significativas quanto à escolaridade e à situação conjugal: pessoas com escolaridade mais alta ou que viviam com parceiro(a) obtiveram médias mais elevadas nessa modalidade de suporte. Quanto ao suporte instrumental, verificou-se diferença significativa apenas em relação à situação conjugal, com a média mais elevada das pessoas que viviam com parceiro(a) (Tabela 3).

\section{As fontes de suporte social}

As fontes de suporte social instrumental e emocional mencionadas pelos participantes estão apresentadas na Tabela 4. Observou-se que as fontes diferiram de acordo com a modali-

Tabela 2. Análises descritivas do suporte social emocional e do suporte social instrumental ( $N=227)$.

\begin{tabular}{|c|c|c|c|c|c|c|c|}
\hline Variáveis & Média & DP & Moda & Mediana & Curtose & Simetria & Amplitude \\
\hline Suporte emocional & 3,85 & 0,79 & 5,0 & 3,92 & $-0,65$ & $-0,41$ & $1,50-5,00$ \\
\hline Suporte instrumental & 3,62 & 0,76 & 4,0 & 3,75 & $-0,18$ & $-0,56$ & $1,30-5,00$ \\
\hline
\end{tabular}

Tabela 3. Médias do suporte social emocional e instrumental segundo sexo, escolaridade, situação conjugal e condição clínica ( $N=227)$.

\begin{tabular}{|c|c|c|c|c|}
\hline & Suporte emocional & $\mathbf{M}$ & DP & $t$ \\
\hline \multirow{2}{*}{ Sexo } & Homens & 3,80 & 0,80 & \multirow{2}{*}{$-0,20$} \\
\hline & Mulheres & 3,88 & 0,81 & \\
\hline \multirow{2}{*}{ Escolaridade } & $\leq$ ensino médio incompleto & 3,71 & 0,85 & \multirow{2}{*}{$-2,50 *$} \\
\hline & $\geq$ ensino médio completo & 3,98 & 0,75 & \\
\hline \multirow{2}{*}{ Situação conjugal } & Vive com parceiro/a & 4,04 & 0,77 & \multirow{2}{*}{$2,80 * *$} \\
\hline & Vive sem parceiro/a & 3,74 & 0,80 & \\
\hline \multirow{2}{*}{ Condição clínica } & Assintomático & 3,98 & 0,77 & \multirow{2}{*}{1,73} \\
\hline & Sintomático & 3,79 & 0,80 & \\
\hline & Suporte instrumental & $\mathbf{M}$ & DP & $t$ \\
\hline \multirow{2}{*}{ Sexo } & Homens & 3,64 & 0,78 & \multirow{2}{*}{$-0,66$} \\
\hline & Mulheres & 3,71 & 0,69 & \\
\hline \multirow{2}{*}{ Escolaridade } & $\leq$ ensino médio incompleto & 3,61 & 0,80 & \multirow{2}{*}{$-0,89$} \\
\hline & $\geq$ ensino médio completo & 3,70 & 0,71 & \\
\hline \multirow{2}{*}{ Situação conjugal } & Vive com parceiro/a & 3,88 & 0,60 & \multirow{2}{*}{$3,9 * * *$} \\
\hline & Vive sem parceiro/a & 3,51 & 0,81 & \\
\hline \multirow{2}{*}{ Condição clínica } & Assintomático & 3,74 & 0,74 & \multirow{2}{*}{1,48} \\
\hline & Sintomático & 3,57 & 0,77 & \\
\hline
\end{tabular}

$* p \leq 0,05 \quad * * p \leq 0,01 \quad * * * p \leq 0,001$ 
dade de suporte. A fonte de suporte social instrumental mais freqüiente foi o(a) parceiro(a) - cônjuge, companheiro(a) ou namorado(a) - seguido dos familiares que residiam com a pessoa, dos familiares que não moravam com o paciente e dos amigos. Na categoria outros, os participantes fizeram referência a pessoas de instituições religiosas e não-governamentais ligadas ao HIV/aids, como o Grupo Arco-Íris e a Fraternidade Assistencial Lucas Evangelista (Fale), entidade que abriga cerca de 120 pessoas vivendo com HIV/aids, localizada no Recanto das Emas/DF.

Quanto ao suporte emocional, os profissionais de saúde, uma categoria de suporte formal diferentemente das demais, foi mencionada em primeiro lugar, seguida dos amigos, dos familiares que não residiam com o paciente e do(a)(s) parceiro(a)(s). Na categoria outros também foram feitas referências a entidades religiosas e a pessoas soropositivas que freqüentavam as ONGs e aos grupos de pacientes em acompanhamento psicológico.

A frequiência das fontes de suporte mencionadas dependeu da ocorrência do relacionamento social na vida da pessoa. Não obstante, pode-se concluir que o suporte instrumental foi disponibilizado por pessoas mais próximas do ponto de vista geográfico, pois as duas categorias que obtiveram maior frequiência referiram-se a pessoas que moravam com o paciente. No caso do suporte emocional, a relação de confiança e o vínculo estabelecido com a pessoa soropositiva pareceram determinar a disponibilidade e satisfação com o apoio recebido.

Tabela 4. Freqüência das fontes de suporte social instrumental e emocional mencionadas pelos participantes ( $N=227)$.

\begin{tabular}{lcc}
\hline Fontes de suporte social & Instrumental & Emocional \\
\cline { 2 - 3 } & $\boldsymbol{f}^{\boldsymbol{1}}$ & 111 \\
Esposa(o), companheira(o) ou namorada(o) & 106 & 96 \\
Familiares que residem com o paciente & 103 & 124 \\
Familiares que não residem com o paciente & 95 & 156 \\
Amigo(s) & 74 & 38 \\
Colega(s) de trabalho & 24 & 22 \\
Vizinho(s) & 8 & 166 \\
Profissional(is) de saúde & 40 & 43 \\
Outro(s) & 54 & \\
\hline
\end{tabular}

Nota ${ }^{1}$ : Mais de uma fonte de suporte foi mencionada pelos participantes.

\section{Discussão}

A estrutura fatorial encontrada foi clara com o agrupamento dos itens em dois fatores: suporte social emocional e instrumental. A grande maioria dos itens mostrou-se adequada, sendo que apenas dois deles foram suprimidos. Assim, é possível concluir que a estrutura fatorial observada correspondeu à estrutura fatorial esperada de um instrumento destinado a medir as principais dimensões do suporte social funcional. Os indicadores de confiabilidade mostraram boa consistência interna, o que demonstra a adequação psicométrica do instrumento.

Por outro lado, a estrutura encontrada na solução unifatorial também se mostrou satisfatória quanto aos indicadores psicométricos e se coaduna com o construto na medida em que se verificou alguma correlação entre as duas modalidades de suporte. É possível concluir que a presente escala permite uma ampla utilização, tanto em pesquisa quanto na prática clínica. Ou seja, permite avaliar disponibilidade e satisfação, de modo integrado e em separado, em relação a diferentes dimensões do suporte emocional e instrumental. Possibilita ainda uma avaliação mais abrangente do suporte social, integrando todos os aspectos, em sua versão unifatorial.
A relevância da mensuração da satisfação com o apoio social constitui uma tendência clara da literatura (Winemiller \& cols., 1993). A satisfação com o suporte percebido é expressão do aspecto subjetivo, pois as pessoas variam imensamente quanto à necessidade objetiva de apoio emocional ou instrumental. Assim, evidencia-se que, ao lado da quantidade ou da freqüência do suporte emocional ou instrumental percebido, é importante avaliar a satisfação das pessoas com o apoio que vem sendo disponibilizado.

O suporte social em sua concepção funcional tem se mostrado de grande importância teórica e metodológica, exemplificada pelos estudos que se nortearam por essa conceituação (Winemiller \& cols., 1993). Na área de saúde, o interesse pelos aspectos funcionais do suporte é evidente, tendo em vista o componente estressor de grande parte dos agravos à saúde, em especial os crônicos. No caso da aids, o estigma que ainda cerca a enfermidade pode afetar a rede de apoio social das pessoas soropositivas, reduzindo a disponibilidade de interações suportivas e eventualmente aumentando as não suportivas (Ingram, Jones, Fass, Neidig \& Song, 1999). Ademais, diferente de outras enfermidades cuja revelação do diagnóstico não constitui um problema ou objeto de constrangimento, a aids quase sempre traz dúvidas em relação a esse aspecto: se é oportuno contar, para quem, quando e como revelar o diagnóstico. 
Logo, a condição de soropositividade pode prejudicar o suporte social específico relacionado à enfermidade. Nessa perspectiva, o enfoque que valoriza os componentes funcionais do suporte social parece trazer maior contribuição ao tema.

Verificou-se ainda a heterogeneidade da amostra quando se comparou o suporte social com algumas características sociodemográficas. Observou-se maior disponibilidade percebida e satisfação das pessoas que viviam com parceiro(a), resultado que era esperado e que tem tido alguma evidência na literatura sobre suporte social em geral (Thoits, 1995). Assim, pessoas soropositivas casadas ou em união consensual referiram mais apoio e estavam mais satisfeitas com os dois tipos de suporte, se comparadas às que estavam solteiras, separadas, divorciadas ou viúvas. A maior disponibilidade percebida e a satisfação com o suporte instrumental parecem decorrer do fato de que essa modalidade de suporte implica o apoio em questões domésticas, além das operacionais relativas ao tratamento que ocorrem no cotidiano, o que é facilitado pela proximidade espacial entre o provedor e o recebedor do suporte.

$\mathrm{O}$ achado que pessoas com escolaridade mais alta estavam mais satisfeitas e percebiam maior disponibilidade de apoio emocional pode ser atribuído à eventual facilidade desse segmento em falar e partilhar com terceiros sobre a sua enfermidade e, em conseqüência, obter apoio social. Importante ressaltar que parte dessa diferença não pode ser atribuída à diferença entre os gêneros e entre as condições clínicas, uma vez que não foi encontrada diferença relevante entre as médias de homens e mulheres, bem como de pessoas sintomáticas e assintomáticas, nas duas modalidades de suporte social.

Apesar dos esforços empíricos que têm auxiliado na clarificação do conceito, pesquisadores consideram que ainda há muito que fazer e os estudos devem reforçar o foco nos aspectos interacionais e na satisfação com o suporte recebido (Ingram \& cols., 1999; Schmitz \& Crystal, 2000). O tamanho da rede, por exemplo, não parece ser tão relevante quanto à qualidade do suporte recebido (disponibilidade e satisfação), provido por poucas ou mesmo uma pessoa significativa (Hupcey, 1998). Nos contextos de saúde e doença, seria igualmente necessário dar continuidade a estudos que explorassem outras variáveis que sofrem influência do apoio social, como habilidades de enfrentamento, adesão ao tratamento e qualidade de vida (Gonzalez \& cols., 2004; Ribeiro, 2005; Seidl, Zannon \& Tróccoli, 2005). Outra linha de investigação poderia pesquisar os efeitos de novas formas de suporte que emergiram na sociedade atual, como as redes sociais construídas via utilização da internet (Kalichman \& cols., 2003).

\section{Referências}

Cassel, J. C. (1976). The contribution of the social environment to host resistance. American Journal of Epidemiology, 104, 107-123.

Cobb, S. (1976). Social support as a moderator of life stress. Psychosomatic Medicine, 38, 300-314.
Cohen, S. \& Wills, T. A. (1985). Stress and the buffering hypothesis. Psychological Bulletin, 98, 310-357.

DiMatteo, M. R. (2004). Social support and patient adherence to medical treatment: A meta-analysis. Health Psychology, 23, 207-218.

Ferrero, J., Barreto, M. P. \& Toledo, M. (1998). Estrés y salud. Em P.B. Martín, J. Martínez \& M. T.Aliaga (Orgs.), Intervención en psicología clínica y salud (pp. 9-58). Valencia: Promolibro.

Freitas, D. C. (1997). Suporte social e saúde mental. Dissertação de Mestrado, Universidade de Brasília, Brasília.

Friedland, J., Renwick, R. \& McColl, M. (1996). Coping and social support as determinats of quality of life in HIV/AIDS. AIDS Care, 8, 15-31.

Fukunishi, I., Hosaka, T., Negishi, M., Moriya, H., Hayashi, M. \& Matsumoto, T. (1997). Avoidance coping behaviors and low social support are related to depressive symptoms in HIV - positive patients in Japan. Psychosomatics, 38, 113-118.

Gonzalez, J. S., Penedo, F. G., Antoni, M. H., Duran, R. E., McPherson-Baker, S., Ironson, G. \& Schneiderman, N. (2004). Social support, positive states of mind and HIV treatment adherence in men and women living with HIV/AIDS. Health Psychology, 23, 413-418.

Green, G. (1993). Editorial review: Social support and HIV. AIDS Care, 5, 87-104.

Holahan, C. J., Holahan, C. K., Moos, R. H. \& Brennan, P. L. (1995). Social support, coping and depressive symptons in a late-middle-aged sample of patients reporting cardiac illness. Health Psychology, 14, 152-163

Hupcey, J. E. (1998). Social support: Assessing conceptual coeherence. Qualitative Health Research, 8, 304-318.

Ingram, K. M., Jones, D. A., Fass, R. J., Neidig, J. L. \& Song, Y. S. (1999). Social support, and unsupportive social interactions: their association with depression among people living with HIV. AIDS Care, 11, 313-329.

Kalichman, S. C., Benotsch, F. G., Weinhardt, L., Austin, J., Luke, W. \& Cherry, C. (2003). Health-related internet use, coping, social support and health indicators in people living with HIV/ AIDS: preliminary results from a community survey. Health Psychology, 22, 111-116.

Klunklin, P. \& Harrigan, R. C. (2002). Child-rearing practices of primary caregivers of $\mathrm{HIV}$-infected children: An integrative review of the literature. Journal of Pediatric Nursing, 17, 289-296.

Leserman, J., Jackson, E. D., Petitto, J. M., Golden, R. N., Silva, S. G., Perkins, D., Cai, J., Folds, J. D. \& Evans, D. L. (1999). Progression to AIDS: The effects of stress, depressive symptoms and social support. Psychossomatic Medicine, 61, 397-406.

Leserman, J., Petitto, J. M., Golden, R.N,. Gaynes, B.N., Gu, H., Perkins, D.O., Silva, S.G., Folds, J.D. \& Evans, D.L. (2000). Impact of stressful life events, depression, social support, coping and cortisol on progression to Aids. American Journal of Psychiatry, 157, 1221-1228.

Lovisi, G. M. \& Morgado, A. F. (1996). Suporte social e distúrbios psiquiátricos em mulheres infectadas pelo HIV. Jornal Brasileiro de Psiquiatria, 45, 593-599.

McNally, S. T. \& Newman, S. (1999). Objective and subjective conceptualizations of social support. Journal of Psychosomatic Research, 46, 309-314. 
Penninx, B. W. J. H., van Tilburg, T. A., Boeke, J. P., Deeg, D. J. H., Kriesgsman, M. W. \& Eijk, J. T. (1998). Effects of social support and personal coping resources on depressive symptoms: Different for various chronic diseases? Health Psychology, 17, 551-558.

Renwick, R., Halpen, T., Rudman, D. \& Friedland, J. (1999). Description and validation of a measure of received support specific to HIV. Psychological Reports, 84, 663-673.

Ribeiro, Y. H. C. P. (2005). Suporte social e qualidade de vida em pessoas portadoras de lesão medular traumática. Dissertação de Mestrado, Universidade de Brasília, Brasília, DF.

Schmitz, M. F. \& Crystal, S. (2000). Social relations, coping, and psychological distress among persons with HIV/AIDS. Journal of Applied Social Psychology, 30, 665-685.

Seidl, E. M. F. (2001). Pessoas vivendo com HIV/Aids: configurando relações entre enfrentamento, suporte social e qualidade de vida. Tese de Doutorado, Universidade de Brasília, Brasília.

Seidl, E. M. F., Tróccoli, B. T. \& Zannon, C. M. L. C. (2001). Análise fatorial de uma medida de estratégias de enfrentamento. Psicologia: Teoria e Pesquisa, 17(3), 225-234.

Seidl, E. M. F., Zannon, C. M. L. C. \& Tróccoli, B. T (2005). Pessoas vivendo com HIV/aids: enfrentamento, suporte social e qualidade de vida. Psicologia Reflexão e Crítica, 18(3), 188-195.

Singh, N., Berman, S. M., Swindells, S., Justis, J. C., Mohr, J. A., Squier, C. \& Wagener, M. M. (1999). Adherence of Human Immunodeficiency Virus-Infected patients to antiretroviral therapy. Clinical Infectious Diseases, 29, 824-830.
Symister, P. \& Friend, R. (2003). The influence of social support and problematic support on optimism and depression in chronic illness: A prospective study evaluating self-esteem as a mediator. Health Psychology, 22, 123-129.

Tabachnick, G. B. \& Fidell, L. S. (1996). Using Multivariate Statistics. New York: HarperCollins.

Thoits, P. A. (1982). Conceptual, methodological and theoretical problems instudying social support as a buffer against life stress. Journal of Health and Social Behavior, 23, 145-159.

Thoits, P. A. (1995). Stress, coping and social support processes: Where are we? What next? Journal of Health and Social Behavior, Extra Issue, 53-79.

Turner, H. A., Pearlin, L. I. \& Mullan, J. T. (1998). Sources and determinants of social support for caregivers of persons with AIDS. Journal of Health and Social Behavior, 39, 137-151.

Winemiller, D. R., Mitchell, M. E., Sutliff, J. \& Cline, D. J. (1993). Measurement strategies in social support: A descriptive review of the literature. Journal of Clinical Psychology, 49, 638-646.

Recebido em 16.12.2005

Primeira decisão editorial em 06.04.2006

Versão final em 08.06.2006

Aceito em 10.10.2006 